essentially a clinical text. It is assumed that the reader already has a sound knowledge of the anatomy, physiology and biochemistry of the gut and liver. I doubt if this assumption is justified and I suspect that many will read it without understanding the pathophysiology of the disorders which are discussed.

The book is well written. Most of the advice is sound. But in the quest for brevity, inevitable errors have crept in. Few would agree that the success of duodenal ulcer therapy must be judged by symptomatic response and endoscopy! In the differential diagnosis of appendicitis, no mention is made of non-specific abdominal pain, unless this subsumed under the term mesenteric adenitis. With modern techniques for the diagnosis of obstructive jaundice, the diagnosis of carcinoma of the bile duct should be made before surgery reveals a swollen liver and collapsed bile ducts. Serum ferritin is almost always elevated in untreated haemochromatosis. Endoscopic cholangiography is more useful to demonstrate bile ducts which do not appear dilated on ultrasound; it is not a straightforward alternative to percutaneous cholangiography. Such errors, of course, occur in all short texts.

In a recent bookseller's list, this was one of nine low-priced books on gastroenterology aimed at the same market. I have grave reservations about the value of any of them. They are rarely of value when dealing with individual patient problems. It may appear idealistic, but I believe we should discourage the use of books written, and certainly read, with examinations in mind. Surely our students should be learning to use the reference sources to which they can turn for practical help after qualification.

However, if students are going to go for a short textbook, at least Professor Langman's has the advantages of clarity and low cost. N. MCINTYRE,

Royal Free Hospital. London NW3 2QG.

\section{Inequalities in Health, The Black Report}

By Douglas Black, J. N. Morris, Cyril Smith and Peter Townsend. Edited by PeTER TOWNSEND and Nick DAVIDSON. Pp. 240, illustrated. Penguin Books, London, 1982. £2.50.

Though our press assumes, for the most part, that mass literacy is useful only for entertainment, government white papers can, in the right circumstances, be best sellers. The Beveridge Report, published in 1942, sold over a million copies to the general public, and a Gallup poll, taken only 2 weeks after its publication, showed that 19 out of every 20 adults were familiar with its main provisions. No one suggests that the Black Report will attain these sales, but mass printing in paperback 2 years after its original publication as 260 duplicated copies on a bank holiday weekend, complete with a dismissive preface by Secretary of State Patrick Jenkins, is a considerable achievement.

Sir Douglas Black has a wry wit. Peter Townsend, Jerry Morris and Cyril Smith write with passion, but none would attribute success to any best-selling qualities of their own: like Beveridge, they chose the right theme at the right time.

Of course, the times are entirely different. The Beveridge Report was seized by the people as a promise of a new world after the war. The unexpected scale of their response made it a de facto declaration of war aims. a huge boost to morale at a critical point in the war. The Black Report, on the other hand, is armament for resisting the dismantling of the health and other social services by our own government. It offers not only conclusive documentation of and argument against our increasing social polarisation in health status, but also a defined and (contentiously) costed package for first steps in dealing with the problem. ready to be taken up by opposition parties. Its wide circulation through this paperback edition could make health care a subject of well-informed debate in the run-up to the next election, and doctors who have not yet read it should take this opportunity to do so. The shortening of the original report is entirely to its advantage: all its important data remain, in a more digestible form.

This will almost certainly be the main field of battle on which the future of our health service will be determined. Whatever their present views, none working in the NHS can afford not to read it.

J. T. HART,

Port Talbot,

Glamorgan SA13 3BL

Long-term Prescribing. Drug Management of Chronic Disease and Other Problems

Edited by ERIC WILKES. Pp. 269, illustrated. Faber \& Faber, London, 1982. $£ 15.00$ (cased), $£ 10.00$ (paper-cover).

This book, edited by a professor of Community Care and General Practice, is written mainly by consultants in various disciplines from Sheffield with some chapters by other specialists and 2 general practitioners. The intended audience is not clearly defined, but it can be inferred from the introduction that it is intended for general practitioners of all grades of seniority. Arrangement of the book is by topic, thus the first chapters cover ischaemic heart disease, hypertension and chronic bronchitis. In each chapter the place of non-drug measures is properly placed before that of specific pharmacotherapy. Each chapter is succinct, clear, digestible and accurate.

Some chapters are a little thin-particularly those on thyroid disease and psychotropic prescribing, and I would like to see a contribution on the principles of drug selection, placebo responses and patterns of prescribing in the next edition. I enjoyed reading this book immensely, and can recommend it wholeheartedly to hospital doctors as well as general practitioners as a useful refresher for prescribing in chronic disease.

R. M. Pearson,

St Bartholomew's Hospital, London EC1A 7BE.

Obstetric Analgesia and Anaesthesia: Current Reviews in Obstetrics and Gynaecology, 1

By J. Selwyn Crawford. Pp. 154. Churchill Livingstone, Edinburgh and London, 1982. $£ 6.00$.

The intended audience of this book is obstetricians studying for their membership examination and those who wish to update themselves in obstetric analgesia and anaesthesia. This it does very comprehensively and must be a valuable guide. In particular it draws upon $\mathrm{Dr}$ Crawford's extensive personal experience and consequently is able to offer its reader many practical tips particularly in relation to the provision of epidural analgesia. Although some of the views expressed are controversial, the book is very well referenced and does not only present the author's personal views.

There are one or two obvious typographical errors: in particular on p. 29 in the fourth paragraph 'preparatory anticholinesterase' should read 'anticholinergic' and on p. 32 'the more soluble the drug' should be 'insoluble'.

This book reflects the high standards of obstetric anaesthetic practice in Dr Crawford's unit and is well worth $\mathbf{E 6}$.

G. COOPER,

Royal Infirmary, Bristol BS2 8HW.

\section{Poisoning, Diagnosis and Treatment}

Edited by J. A. VAle and T. J. Meredith. Pp. xi+220. illustrated. Update Books (Publishers) MTP Press, Lancaster. 1981. $£ 13.50$ (hardback), $£ 11.00$ (paperback).

This book deserves its place in the Update series, for it combines an educative role on the mechanisms underlying chemical toxicity, drug and non-drug, in man, with detailed helpful discussions on patient management.

It is written by a group of authors with considerable experience in the treatment of poisoning. Recent advances in analytical techniques and in methods to assist drug elimination and maintain vital 